\title{
Docking and dynamic simulation study of Crizotinib and Temozolomide drug with Glioblastoma and NSCLC target to identify better efficacy of the drug
}

\author{
Saleena Younus ${ }^{1 *}$ (D) S. S. Vinod Chandra ${ }^{2}$ and Achuth Sankar S. Nair ${ }^{1}$
}

\begin{abstract}
Background: Crizotinib and Temozolomide are the two major chemotherapy drugs used for the treatment of cancers. Crizotinib is used as a target chemotherapy drug in many cancers. It mainly binds on the ATP binding regions of receptor tyrosine kinases (RTKs) targets and inhibits protein phosphorylation, which has already been reported. Temozolomide drug is known as the alkylating agent. Its mechanism of action is the methylation of DNA and thereby inhibiting DNA replication. However, the Temozolomide drug with protein level interaction of Glioblastoma Multiforme (GBM) and Non-small-cell lung carcinoma (NSCLC) of RTKs targets has not been reported so far. In the proposed work, we investigated the molecular level interaction of the Temozolomide drug in C-MET, C-ROS1, and ALK RTKs targets of GBM and NSCLC using an in silico study. We performed comparative analysis studies in both drugs' docked complexes based on their drug properties and complex energy (CE) to identify the better efficacy of the drug.

Results: From the docking studies, we could identify that the Temozolomide drug bounded protein complexes showed the least complex energy. The most stable complexes were identified from these docking studies by Molecular Dynamic simulation. In the proposed study, we found that the docked complex attained a stable conformation and least energy via solid hydrogen bond interactions between the amino acid residues and the drug at the binding sites of the proteins. The least energy and the hydrogen bond interaction of Temozolomide drug with the amino acid residues of the protein complexes of C-MET, C-ROS1 and ALK protein with their id name are: 2 WGJ is -11305.0830 (PRO1158, MET1160), 3ZBF is - 11,659.6814 (MET2029, GLU2027), and 2XP2 is - 11,734.7565 (ARG1275, ASP 1160, GLU1167).
\end{abstract}

Conclusion: Our studies revealed that the Temozolomide drug bounded protein complex showed the least energy when compared to Crizotinib. So it will give better interaction on the binding sites of proteins and thereby provide better inhibition in the treatment of target therapy of GBM and NSCLC.

Keywords: Glioblastoma multiforme, Lung cancer, Chemotherapy, Target therapy, Alkylating agent, RTKs

\footnotetext{
*Correspondence: saleenans1@gmail.com

${ }^{1}$ Department of Computational Biology and Bioinformatics, University

of Kerala, Kariavattom Campus, Trivandrum, Kerala 695581, India

Full list of author information is available at the end of the article
}

\section{Background}

Glioblastoma or Glioblastoma Multiforme (GBM) and Non-small-cell lung carcinoma (NSCLC) are the two major causes of cancer mortality globally. GBM is listed as the most aggressive, invasive and undifferentiated type of tumor and has been categorized as a Grade IV tumor by WHO. The median overall survival rate of GBM is 
12-15 months, and NSCLC is 15 months [1-3]. The main reason for GBM and NSCLC is the dysregulations of RTKs in C-MET, C-ROS1 and ALK [4]. So C-MET, C-ROS1 and ALK RTKs are considered as the primary therapeutic targets of GBM and NSCLC [5-7] cancers. The main chemotherapy drugs used for GBM and NSCLC are Crizotinib and Temozolomide [8-12].

The present study's objective was to identify which drug is more effective in treating GBM and NSCLC when Crizotinib and Temozolomide are used as the targeted therapy drug in C-MET, C-ROS1 and ALK target of GBM and NSCLC cancers. Drug efficacy is the results from intermolecular level interaction of the drug with protein/DNA/RNA/enzyme molecules, which can be identified with docking software [13]. The intermolecular level interaction of Crizotinib with C-MET, C-ROS1 and ALK of RTKs has already been reported experimentally. The $\mathrm{X}$-ray crystallographic structures have been deposited in the PDB database $[14,15]$ but are not reported in the Temozolomide drug. However, in the Crizotinib bounded protein structures, we could only identify the drug properties based on their intermolecular interaction but not on the complex energy. So we performed docking of both Crizotinib and Temozolomide drugs with the same proteins to identify the better drug.

\section{Methods}

The leading software we used for the docking study was Discovery Studio 2018 (v18.1.100.18065), Server: DCBDELL-DSSERVER1. The primary online resources used for the study were Uniprot, PDB, NCBI, PDBsum and PubChem databases. The 3D structure of target proteins C-MET (Protein id: 2WGJ), C-ROS1 (Protein id: 3ZBF), ALK (Protein id: 2XP2) and drug molecules Temozolomide and Crizotinib were downloaded from PDB and
PubChem databases, respectively $[16,17]$. The $2 \mathrm{D}$ images and chemical properties of both Crizotinib and Temozolomide are shown in Table 1.

\section{Docking}

We performed docking with the LibDock tool (Discovery Studio user manual) of Biovia Discovery Studio 2018 [18]. The LibDock tool allowed flexible docking and is usually used for library docking of compounds. However, we chose the LibDock tool for docking in the current study, because LibDock will generate hundreds of pose conformations for a single drug molecule, and also LibDock will show good scoring accuracy in drug poses. In LibDock, the Ligscore 2 scoring function is used for scoring the drug poses $[19,20]$. The pipeline used for the docking study is shown in Fig. 1.

During preprocessing, the ligand was removed from the protein structures and then performed protein preparation with an automatic preparation tool. This tool performs the main tasks in the input protein structure are standardizing atom names, insert missing atoms in the residues, insert missing loop regions, remove alternate conformations and water molecules. Moreover, optimize short and medium size loop regions with the Looper algorithm, minimize the remaining loop regions and calculate the $\mathrm{pK}$ and protonate the structure. In this tool, the CHARMM force field was applied for minimizing the entire protein structures [21]. The drug molecules Crizotinib and Temozolomide were prepared and minimized before the docking using Discovery Studio 2018. In the minimization of ligand, a maximum of 2000 steps was performed by smart minimizer algorithm. The RMS gradient was set as 0.01 . After this, we identified the active site of the protein by the following methods.

Table 1 List of ligands with CAS number which used for the study

\begin{tabular}{|c|c|c|c|c|c|c|c|c|}
\hline SI.NO: & Ligand name & CAS number & Molecular formula & MW & $\log P$ & $\begin{array}{l}\text { H-bond } \\
\text { donors }\end{array}$ & $\begin{array}{l}\text { H-bond } \\
\text { acceptors }\end{array}$ & Chemical structure \\
\hline 1 & $\begin{array}{l}\text { Crizotinib (3-[(1R)-1-(2,6-dichloro- } \\
\text { 3-fluorophenyl)ethoxy]-5-(1-piperi- } \\
\text { din-4-ylpyrazol-4-yl)pyridin-2-amine) }\end{array}$ & $877399-52-5$ & $\mathrm{C}_{21} \mathrm{H}_{22} \mathrm{Cl}_{2} \mathrm{FN}_{5} \mathrm{O}$ & $450.3 \mathrm{~g} / \mathrm{mol}$ & 1.83 & 2 & 6 & \\
\hline 2 & $\begin{array}{l}\text { Temozolomide (3-methyl- } \\
\text { 4-oxoimidazo[5,1-d][1,2,3,5] } \\
\text { tetrazine-8-carboxamide) }\end{array}$ & $85622-93-1$ & $\mathrm{C}_{6} \mathrm{H}_{6} \mathrm{~N}_{6} \mathrm{O}_{2}$ & $194.15 \mathrm{~g} / \mathrm{mol}$ & -2.8 & 1 & 5 & \\
\hline
\end{tabular}




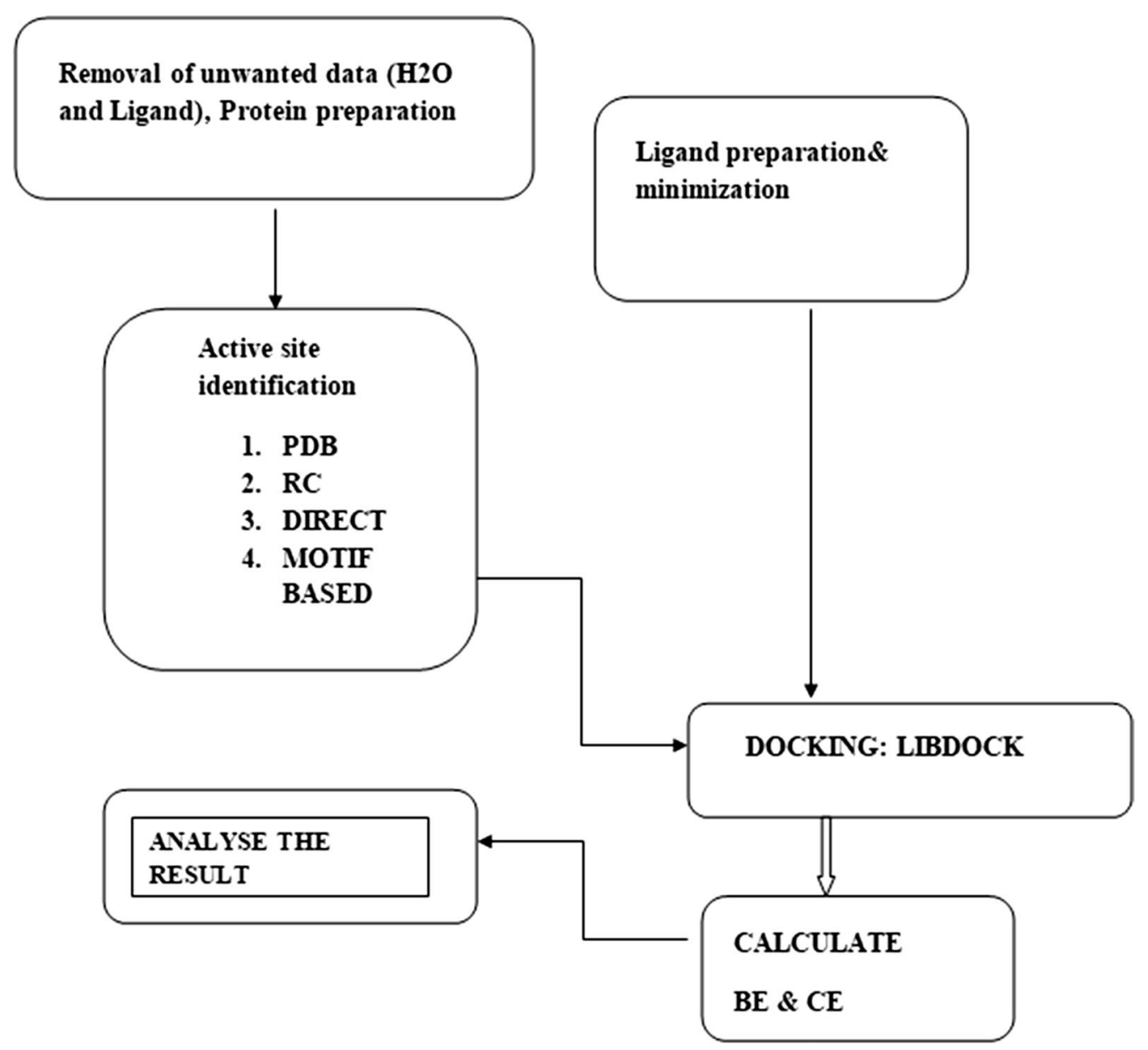

Fig. 1 Pictorial representation of pipeline used in the in silico study

PDB Site record: In this method, the tool identifies the already reported binding site from the PDB file, and this site is used as active sites of the protein.

Receptor Cavity $(R C)$ : This method derives the binding sites from the protein's cavity structure.

Direct/Site-specific method: In this method, we can directly define the protein's binding site if we have prior knowledge about it.

Motif based method: In this method, we selected the already reported active site of each protein and its DFGmotif region as a binding site. The reason is that the DFG motif has a crucial role in the regulation of kinase protein activity. So DFG-motif of kinase protein is considered as one of the critical parts of structure-based drug designing [22].

The docking is performed for each drug with the protein based on the active site identification. Then the binding energy and complex (CE) energy of the docked complex was calculated. We selected the docked complex's top 10 poses from each docking method to calculate the binding energy and complex energy using calculate Binding Energy tool of Discovery Studio 2018. The binding energy and CE are calculated by using the following equations in Discovery Studio software.

$$
\begin{aligned}
\text { Energy binding }= & \text { Energy complex }- \text { Energy ligand } \\
& - \text { Energy receptor. } \\
\text { Complex energy }= & \text { Energy binding }+ \text { Energy ligand } \\
& + \text { Energy receptor. }
\end{aligned}
$$

The final result of each docking method was evaluated based on drug properties and complex energy. Crizotinib drug property is an inhibitor of receptor tyrosine kinases (RTKs), which binds the ATP binding region of tyrosine kinase protein and inhibits the protein from phosphorylation. Here the active sites of Crizotinib on 


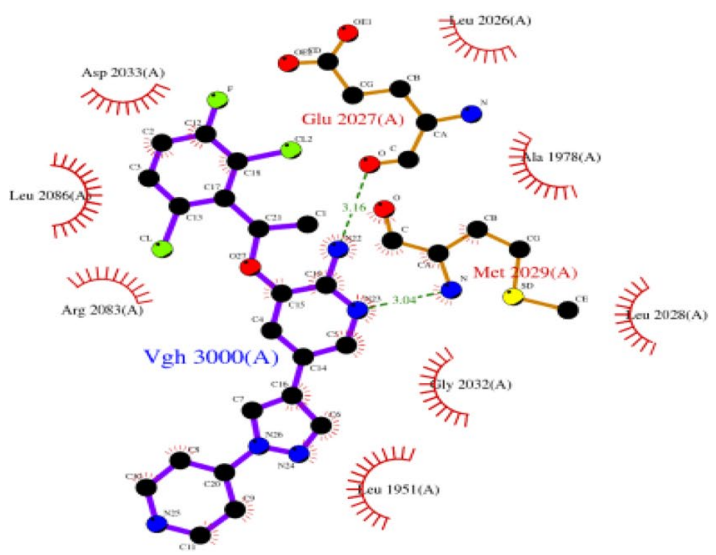

2WGJ (C-MET)

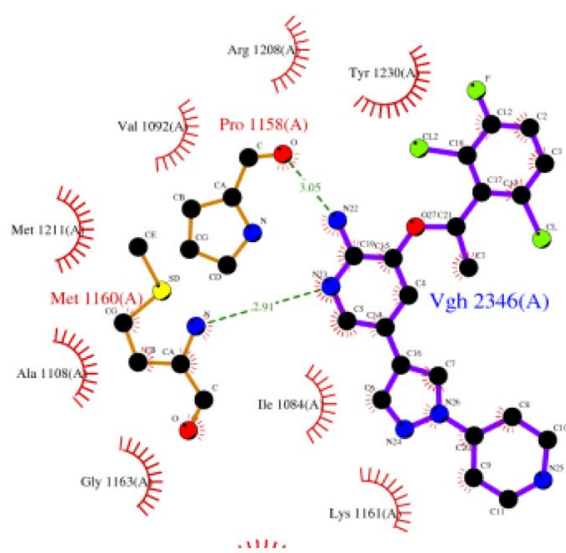

3ZBF(C-ROS1)

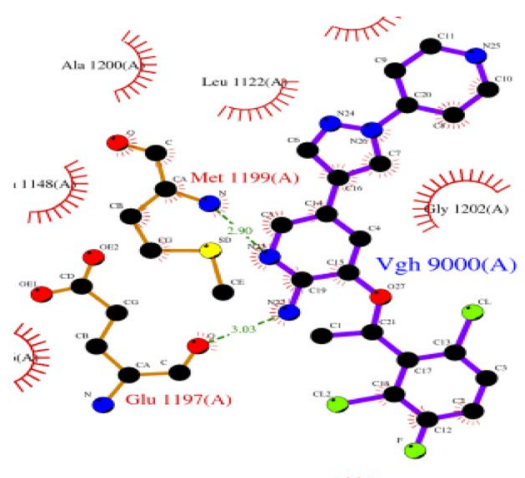

2XP2(ALK)

Fig. 2 Molecular interaction of Crizotinib drug with 2WGJ, 3ZBF and 2XP2. In 2WGJ, primary interaction occurs in the ATP binding sites are Glu2027, Met2029, in 3ZBF, found in Pro1158, Met 11,600 and 2XP2 protein, Glu1197, Met1199 amino acid residues. These hydrogen bond interactions are displayed as green color in the image

targeted protein experimentally reported by X-ray crystallographic structure were Pro1158, Met1160 in 2WGJ (C-MET), Glu2027, Met2029 in 3ZBF (C-ROS1) and Glu1197, Met1199 in 2XP2 (ALK), which are shown in Fig. 2.

Temozolomide drug is an alkylating agent. Its mechanism of action is methylation, which has an essential role in regulating protein functions. It is already reported that methylation by Temozolomide drug occurs in arginine and lysine residues of the protein [23]. In eukaryotes organism, methylation usually occurs on the side-chain nitrogen of glutamate, leucine, isoprenylated cysteine, lysine, arginine, histidine residues or the carboxyl groups of proteins [24-28, 33]. Hence, the docking of Temozolomide drug with C-MET, C-ROS1 and ALK proteins focuses on the interaction on these amino acid residues and already reported key residues at the proteins' binding sites.

\section{Dynamic simulation}

To analyze the least energy showed complexes' stability and conformational flexibility in a biological system, we performed Molecular Dynamics (MD) simulation studies [29] using two tool panels of Discovery Studio 2018 (Ref: user manual of Simulation protocol in Discovery Studio Tool). The first one was standard dynamics cascade, and the second one was Analyze Trajectory tool. Here we selected the protein docked complex from C-MET, C-ROS1 and ALK complexes for MD simulations were based on the order of their least complex energy. Before the dynamic simulation study, we applied the CHARMM36 force field in the docked complex using the ChangeForce field tool panel. (In Discovery Studio, CHARMM36 is the default force field applied for changing force field of macromolecules.) Then, docked complex was solvated by adding enough water molecules, 
chloride and sulfur, allowing the protein molecule to naturally interact with the solvent [30] by using the solvation method, which is included in the simulation tool panel. The protein complex solvated was an explicit periodic boundary condition. After setting the solvation condition of the protein complex, started the MD simulation run by using the standard dynamic cascade tool of Discovery Studio 2018. Before running the MD simulation, the parameters were set up. In the minimization part, two minimization methods were used based on steepest descent and adopted basis NR algorithm. The minimization steps were set as 1000 and 2000 on each part, respectively. After setting the energy minimization step, heating, equilibration and production were done.

During heating, the whole system's initial temperature was set from 50 to $300 \mathrm{~K}$ in 4 ps (picosecond) simulation time without restraint, and adjust velocity frequency was set in 50 . The result was saved at interval 2 ps (picoseconds). Next, the equilibration of the system was set to $300 \mathrm{~K}$ temperature, adjust velocity frequency was set to 50 , and the simulation time was set to 20 ps without restraint. Finally, the production time was set to 200 ps for a run in $300 \mathrm{~K}$ with typed NPT. The remaining parameter was set as by default value. The total simulation times taken for the heating, equilibration and production steps were 224 ps. After MD simulation, we checked the hydrogen bond interaction between amino acid residues of the protein and ligand molecule. To understand the complex's conformational stability and flexibility, we performed trajectory analysis by using Analyze Trajectory tool of Discovery Studio 2018. For this, we selected the protein complexes, which were shown stable hydrogen bonds during the MD simulation run. No solvent files of C-MET, C-ROS1 and ALK were chosen as reference molecules for analyzing the trajectory of the C-MET, C-ROS1 and ALK complexes. In the proposed study, we performed two types of MD simulation analysis on each protein to identify the actual deviations and fluctuations that occur in a protein structure when a drug molecule bounded on its active site.

1. MD simulation performed on ligand-free protein structure.

2. MD simulation performed on ligand bounded protein structure based on their least energy.

\section{Results}

Docking result

Docking of protein 2WGJ(C-MET) with Crizotinib has generated 353 drug poses in docking by four different active site identification methods. The PDB site record method generated 93 drug poses in which drug pose number six (P6) showed the least energy and good drug interaction. The least $\mathrm{CE}$ of the docked complex was $-11,179.9569$ and the main interaction showed amino acid residues on the binding site were PRO1158, MET1160 and ASP1164. In the RC method, ten sites had been generated on the protein cavity, in which only two binding sites S1 and S2 showed good drug interaction with the least complex energy. In the S1 site, 99 drug poses and site S2, 65 drug poses were docked. Here the least energy along with good drug interaction showed complex was the drug pose number four in the site $\mathrm{S} 2(\mathrm{RC}(\mathrm{S} 2, \mathrm{P} 4))$. It interacts with the amino acid residue PRO1158, MET1160 and ASP1164, and the least energy of this complex was $-11,155.5712$. In the site-specific/ DIRECT method, we performed docking on the already reported binding region PRO1158, MET1160. Here, a total of 94 drug poses were generated and docked on the site. The second drug pose (P2) formed complex exhibits the least energy with good drug interaction. This complex's least energy was $-11,028.5560$, and the primary interacting amino acid residues found in the binding site were ASP1164, PRO1158, and MET1160. In the motif-based method, we consider the DFG motif Asp1222, Phe1223, Gly1224 of the kinase protein 2WGJ and already reported binding site PRO1158, MET1160. The reason for this was that the DFG motif has a particular role in regulating kinase protein activity. So in the drug development processing of kinase proteins against various diseases in the targeted therapy, the DFG motif is considered one of the vital elements [22]. In the motifbased docking method, only two drug poses were generated and docked on the particular site. However, there were no good drug interactions found in that specific site at the docking.

Docking of Crizotinib with protein 3ZBF(C-ROS1), 287 drug poses generated and docked on different protein sites by various methods. In this docking, 95 drug poses in PDB, 51 drug poses in RC, 67 drugs poses indirect, and 74 drug poses in the motif-based method had docked. In the PDB method, drug pose number six (P6) showed good interaction with the amino acid residues ASP2033, GLU2027, MET2029, and the least energy of this docked complex was $-11,509.9762$. In the RC method, fourteen sites had generated from the protein's cavity, in which only three sites (S1, S4 and S6) were docked with 51 drug poses. Here the least energy showed complex was the docking of drug pose number four (P4) at the protein site S1 (RC (S1, P4)). This docked complex's least energy was $-11,400.4896$, and the primary interaction showed amino acid residues with the drug in the binding region was ASP2033, GLU2027 and MET2029. In the direct method, amino acid residues GLU2027 and MET2029 are considered for docking. Here a total of 67 
drug poses were generated and docked on the selected site. The best-docked complex of this docking was the drug pose number three (P3) with the protein (DIRECT (P3)). The complex's energy was $-11,473.5427$ and the main interacting amino acid residue in the binding site with the drug was GLU2027 MET2029. In the motifbased method, we selected Glu2027, Met2029 amino acid residues, and the DFG motif Asp2102, Phe2103, and Gly2104. Here 74 drug poses were generated and docked at the selected site and the first drug pose (P1) attained good drug interaction on the protein at the amino acid residues ASP2033, GLU2027, MET2029 (MOTIF (P1)). The least energy of this docked complex was $-11,514.2552$.

Docking of Crizotinib with protein 2XP2(ALK), 393 drug poses were generated and docked. In the PDB method, 97 total drug poses generated and docked, in which the least energy with good drug interaction showed complex was the docking of drug pose number ten (P10) at the PDB site (PDB,(P10)). The least energy of the complex was $-11,600.2395$ and the drug interacts with the primary amino acid residues were GLU1197, MET1199. Ten sites had been generated in the RC method, but only two sites, S1 and S2, were docked with 102 drug poses. In this, site S1 with drug pose number eight (P8) showed good drug interaction with least energy (RC (S1 (P8)). The least energy of the docked complex was $-11,666.7948$, and the primary interacting amino acid with the drug in the binding site was GLU1197, MET1199. In the direct method, 100 drug poses were generated and docked on the GLU1197 and MET119. Here, the least energy showed complex was the first drug pose (P1) with the protein site. The main amino acid interaction found on the site was GLU1197, MET1199, SER1206 and ASP1203, and the least energy of the docked complex was $-11,648.2048$. In motifbased docking, a total 94 drug poses were generated on the site and docked. The main amino acid selected for docking was GLU1197, MET 1199 and the DFG motifs were Asp1270, Phe1271 and Gly1272. The best-docked complex obtained from this docking was drug pose number nine (P9) with GLU1197, MET1199 and ASP1203 in the protein. The least energy of this docked complex was $-11,656.9972$.

Tables 2 and 3 contain the drug's details, docking method, binding site, the total drug poses generated, drug pose docked on the binding sites, and druggable binding sites. Tables 4 and 5 contain details of docking score, binding energy, complex energy of the docked complex, and the main hydrogen bond interaction showed amino acid residues at each protein complex's binding site.

In the case of Temozolomide drug with proteins docking, we looked at two types of interactions.

1. The Temozolomide drug interaction with already reported amino acid residues of the proteins.

2. The Temozolomide drug interaction with the main methylation site of the proteins.

Table 2 Details of the docked drug, total drug pose generated in each docking method and details of the druggable binding site

\begin{tabular}{|c|c|c|c|c|c|c|}
\hline Protein Name & Docked drug & Docking method & $\begin{array}{l}\text { Site generated/key amino acid } \\
\text { point selected }\end{array}$ & $\begin{array}{l}\text { Total } \\
\text { drug pose } \\
\text { generated }\end{array}$ & $\begin{array}{l}\text { Drug pose docked } \\
\text { on the total number } \\
\text { of site }\end{array}$ & $\begin{array}{l}\text { Pose number } \\
\text { and druggable } \\
\text { site }\end{array}$ \\
\hline \multirow[t]{4}{*}{ 2WGJ } & \multirow[t]{4}{*}{ Crizotinib } & PDB & 1 & 93 & $1(93)$ & PDB(P6) \\
\hline & & $\mathrm{RC}$ & $10(\mathrm{~S} 1, \mathrm{~S} 2, \mathrm{~S} 3, \mathrm{~S} 4, \mathrm{~S} 5, \mathrm{~S} 6, \mathrm{~S} 7, \mathrm{~S} 8, \mathrm{~S} 9, \mathrm{S10})$ & 164 & $2(\mathrm{~S} 1(99), \mathrm{S} 2(65))$ & $\mathrm{RC}(\mathrm{S} 2, \mathrm{P} 4))$ \\
\hline & & $\begin{array}{l}\text { DIRECT/ } \\
\text { Site-specific }\end{array}$ & 1(Pro1158, Met1160) & 94 & $1(94)$ & DIRECT(P2) \\
\hline & & MOTIF & $\begin{array}{l}\text { 1(Pro1158, Met1160, } \\
\text { DFG motif } \\
\text { Asp1222,Phe1223,Gly1224) }\end{array}$ & 2 & $1(2)$ & NIL \\
\hline \multicolumn{7}{|l|}{$3 Z B F$} \\
\hline & \multirow[t]{4}{*}{ Crizotinib } & PDB & 1 & 95 & $1(95)$ & PDB(P6) \\
\hline & & $\mathrm{RC}$ & $\begin{array}{l}14(\mathrm{~S} 1, \mathrm{~S} 2, \mathrm{~S} 3 \mathrm{~S} 4, \mathrm{~S} 55, \mathrm{~S} 6, \mathrm{~S} 7, \mathrm{~S} 8, \mathrm{~S} 9, \mathrm{~S} 10, \mathrm{~S} 11 \\
\text {,S12,S13,S14) }\end{array}$ & 51 & $\mathrm{S1}(3), \mathrm{S} 4(13), \mathrm{S} 6(35)$ & $\mathrm{RC}(\mathrm{S} 1, \mathrm{P} 4)$ \\
\hline & & DIRECT & 1(Glu2027,Met2029) & 67 & $1(67)$ & $\mathrm{DIRECT}(\mathrm{P} 3)$ \\
\hline & & MOTIF & $\begin{array}{l}\text { 1(Glu2027,Met2029,DFG motif } \\
\text { Asp2102,Phe2103,Gly2104) }\end{array}$ & 74 & $1(74)$ & MOTIF(P1) \\
\hline \multirow[t]{4}{*}{$2 \times P 2$} & \multirow[t]{4}{*}{ Crizotinib } & PDB & 1 & 97 & $1(97)$ & $\mathrm{PDB}(\mathrm{P} 10)$ \\
\hline & & $\mathrm{RC}$ & $10(\mathrm{~S} 1, \mathrm{~S} 2, \mathrm{~S} 3, \mathrm{~S} 4, \mathrm{~S} 5, \mathrm{~S} 6, \mathrm{~S} 7, \mathrm{~S} 8, \mathrm{~S} 9, \mathrm{~S} 10)$ & 102 & $\mathrm{~S} 1(96), \mathrm{S} 2(6)$ & $\mathrm{RC}(\mathrm{S} 1, \mathrm{P} 8)$ \\
\hline & & DIRECT & 1(Glu1197, Met1199) & 100 & $1(100)$ & DIRECT(P1) \\
\hline & & MOTIF & $\begin{array}{l}\text { 1(Glu1197,Met1199,DFG motif } \\
\text { Asp1270,Phe1271,Gly1272) }\end{array}$ & 94 & $1(94)$ & MOTIF(P9) \\
\hline
\end{tabular}


Table 3 Details of the docked drug, total drug pose generated in each docking method and details of the druggable binding site

\begin{tabular}{|c|c|c|c|c|c|c|}
\hline Protein Name & Docked drug & Docking method & $\begin{array}{l}\text { Site generated/key amino } \\
\text { acid point selected }\end{array}$ & $\begin{array}{l}\text { Total } \\
\text { drug pose } \\
\text { generated }\end{array}$ & $\begin{array}{l}\text { Drug pose docked on the } \\
\text { total number of site }\end{array}$ & $\begin{array}{l}\text { Pose number } \\
\text { and druggable } \\
\text { site }\end{array}$ \\
\hline \multirow[t]{5}{*}{ 2WGJ } & Temozolomide & & & & & \\
\hline & & PDB & 1 & 43 & $1((43)$ & $\mathrm{PDB}(\mathrm{P9}), \mathrm{PDB}(\mathrm{P} 4)$ \\
\hline & & $\mathrm{RC}$ & $\begin{array}{l}5(\mathrm{~S} 1, \mathrm{~S} 2, \mathrm{~S} 3, \mathrm{~S} 4, \mathrm{~S} 5, \mathrm{~S} 6, \mathrm{~S} 7, \mathrm{~S} 8, \mathrm{~S} \\
9, \mathrm{~S} 10)\end{array}$ & 62 & $4(\mathrm{~S} 1(7), \mathrm{S} 2(39), \mathrm{S} 4(3), \mathrm{S} 6(13))$ & $(\mathrm{RC}(\mathrm{S} 1, \mathrm{P} 4),(\mathrm{S} 1, \mathrm{P} 6))$ \\
\hline & & DIRECT & 1(Pro1158, Met1160) & 29 & $1(29)$ & DIRECT(P4) \\
\hline & & MOTIF & $\begin{array}{l}\text { 1(Pro1158, Met1160, } \\
\text { DFG motif } \\
\text { Asp1222,Phe1223,Gly1224) }\end{array}$ & 13 & $1(13)$ & MOTIF(P1,P11) \\
\hline \multirow[t]{5}{*}{$3 Z B F$} & Temozolomide & & & & & \\
\hline & & PDB & 1 & 51 & $1(51)$ & $\mathrm{PDB}(\mathrm{P} 3, \mathrm{P} 4)$ \\
\hline & & $\mathrm{RC}$ & $\begin{array}{l}14(\mathrm{~S} 1, \mathrm{~S} 2, \mathrm{~S} 3, \mathrm{~S} 4, \mathrm{~S} 5, \mathrm{~S} 6, \mathrm{~S} 7, \mathrm{~S} 8, \mathrm{~S} 9 \\
\mathrm{S} 10, \mathrm{~S} 11, \mathrm{~S} 12, \mathrm{~S} 13, \mathrm{~S} 14)\end{array}$ & 105 & $\begin{array}{l}\mathrm{S} 1(32), \mathrm{S} 4(30), \mathrm{S} 6(33), \mathrm{S} 8(6), \mathrm{S} 10 \\
(1), \mathrm{S} 11(3)\end{array}$ & $\mathrm{S} 1(\mathrm{P} 4, \mathrm{P} 9)$ \\
\hline & & DIRECT & 1(Glu2027,Met2029) & 100 & $1(100)$ & DIRECT(P5) \\
\hline & & MOTIF & $\begin{array}{l}\text { 1(Glu2027,Met2029, } \\
\text { DFG motif } \\
\text { Asp2102,Phe2103,Gly2104) }\end{array}$ & 94 & $1(94)$ & MOTIF(P1) \\
\hline \multirow[t]{5}{*}{$2 X P 2$} & Temozolomide & & & & & \\
\hline & & PDB & 1 & 51 & $1(51)$ & PDB(P3) \\
\hline & & RC & $\begin{array}{l}10(\mathrm{~S} 1, \mathrm{~S} 2, \mathrm{~S} 3, \mathrm{~S} 4, \mathrm{~S} 5, \mathrm{~S} 6, \mathrm{~S} 7, \mathrm{~S} 8, \mathrm{~S} \\
9, \mathrm{~S} 10)\end{array}$ & 40 & $\begin{array}{l}\mathrm{S} 1(5), \mathrm{S} 2(19), \mathrm{S} 6(2), \mathrm{S} 7(7), \mathrm{S} 8(2 \\
), \mathrm{S} 10(5)\end{array}$ & $\mathrm{RC}(\mathrm{S} 1(\mathrm{P} 2, \mathrm{P} 4))$ \\
\hline & & DIRECT & 1(Glu1197,Met1199) & 5 & $1(5)$ & DIRECT(P3) \\
\hline & & MOTIF & $\begin{array}{l}\text { 1(Glu1197,Met1199,DFG } \\
\text { motif } \\
\text { Asp1270,Phe1271,Gly1272) }\end{array}$ & 3 & $1(3)$ & MOTIF(P2) \\
\hline
\end{tabular}

Table 4 The details of the druggable binding site, their docking score and binding energy, least complex energy and the main interaction showed amino acid residues at the binding site

\begin{tabular}{llllll}
\hline $\begin{array}{l}\text { Protein name and } \\
\text { drug name }\end{array}$ & Type of docking & Docking score & $\begin{array}{l}\text { Binding energy } \\
\text { (kcal/mol) }\end{array}$ & $\begin{array}{l}\text { Complex energy } \\
\text { (kcal/mol) }\end{array}$ & Interacting residues \\
\hline 2WGJ & PDB(P6) & 139.105 & -44.14 & $-11,179.9569$ & MET1160,PRO1158,ASP1164 \\
DRUG-CRIZOTINIB & RC(S2,P4) & 137.169 & -15.3749 & $-11,155.5712$ & ASP1164,PRO1158,MET1160 \\
& DIRECT(P2) & 106.855 & 114.7614 & $-11,028.5560$ & ASP1164,PRO1158,MET1160 \\
& MOTIF & - & - & - & - \\
3ZBF & PDB(P6) & 113.349 & -106.9428 & $-11,509.9762$ & ASP2033,GLU2027,MET2029 \\
DRUG-CRIZOTINIB & RC(S1,P4) & 92.346 & 62.0108 & $-11,400.4896$ & GLU2027,MET2029 \\
& DIRECT(P3) & 98.9302 & -20.1590 & $-11,473.5427$ & GLU2027,MET2029 \\
& MOTIF(P1) & 114.545 & -112.0438 & $-11,514.2552$ & ASP2033,GLU2027, MET2029 \\
2XP2 & PDB(P10) & 111.801 & -135.9488 & $-11,600.2395$ & GLU1197, MET1199 \\
DRUG-CRIZOTINIB & RC(S1,P8) & 108.615 & -189.7012 & $-11,666.7948$ & GLU1197, MET1199 \\
& DIRECT(P1) & 118.508 & -193.8604 & $-11,648.2048$ & GLU1197,MET1199, ASP1203, \\
& & & & & SER1206 \\
& MOTIF(P9) & 107.35 & -176.1679 & $-11,656.9972$ & GLU1197,MET1199,ASP1203 \\
\hline
\end{tabular}

Docking of Temozolomide drug with 2WGJ protein, 147 drug poses were generated and docked in all the docking methods. In PDB site record method docking, a total of 43 drug poses were generated and docked, in which we selected two different poses complex. The first one is PDB (P4) and the second one is PDB (P9). In the $\mathrm{RC}$ method, a total of 62 drug poses were generated and docked on four sites from ten different docking sites. Here we selected two best-docked complexes with poses were the first site with pose number 4 and pose 
Table 5 The details of the druggable binding site, their docking score and binding energy, least complex energy and the main interaction showed amino acid residues at the binding site

\begin{tabular}{llccll}
\hline Protein name and drug name & Type of docking & docking score & $\begin{array}{l}\text { Binding energy } \\
\text { (kcal/mol) }\end{array}$ & $\begin{array}{l}\text { Complex energy } \\
\text { (kcal/mol) }\end{array}$ & Interacting residues \\
& & & 7.4427 & $-11,266.0096$ & ARG1208 \\
\hline 2WGJ & PDB(P9) & 72.1914 & -16.3492 & $-11,289.7872$ & MET1160 \\
& PDB(P4) & 74.4989 & 20.7625 & $-11,295.5088$ & ARG1227,GLU1127 \\
DRUG-TEMOZOLOMIDE & RC(S1,P6) & 65.8739 & -25.2079 & $-11,302.4869$ & ARG1227 \\
& RC (S1,P4) & 67.5009 & -27.8584 & $-11,305.0830$ & PRO1158, MET1160 \\
& DIRECT(P4) & 68.0813 & -32.2530 & $-11,309.5066$ & ARG1208 \\
& MOTIF(P1) & 74.7354 & -19.8256 & $-11,292.9200$ & PRO1158, MET1160 \\
& MOTIF(P11) & 56.0548 & -21.2784 & $-11,597.8$ & LYS1980,ARG2083 \\
3ZBF & PDB(P3) & 60.5055 & -40.5732 & $-11,659.6814$ & MET2029,GLU2027 \\
& PDB(P4) & 58.5464 & -55.3656 & $-11,670.6518$ & ASP2102 \\
DRUG-TEMOZOLOMIDE & S1(P4) & 54.3362 & -38.8334 & $-11,657.6084$ & LYS1980 \\
& S1(P9) & 51.9164 & -12.0296 & $-11,627.0789$ & GLU2027,MET2029 \\
& DIRECT(P5) & 56.4637 & -29.3576 & $-11,648.4805$ & HIS2006 \\
& MOTIF(P1) & 71.1408 & -3.4005 & $-11,693.1778$ & GLU1197,MET1199 \\
2XP2 & PDB(P3) & 61.6198 & -44.4725 & $-11,734.7565$ & ARG1275, GLU1167 \\
DRUG-TEMOZOLOMIDE & RC(S1,P2) & 60.1738 & $-11,750.1009$ & LYS1150,ARG1275 \\
& RC(S1,P4) & -59.7869 & -59.7869 & $-11,715.3869$ & MET1199 \\
& DIRECT(P3) & 61.0851 & -25.9935 & $-11,717.0798$ & LYS1150,ASP1249,ASP1270
\end{tabular}

number 6((RC (S1,P4),(S1, P6)). In the direct method, a total of 29 drug poses were generated and docked, in which we got good interaction with least energy showed complex on pose number 4(DIRECT (P4)). In the motif method, a total 13 poses were generated and docked. These pose numbers 1 and 11 showed the least energy with good interaction (MOTIF (P1, P11)).

Docking of Temozolomide drug with 3ZBF protein, total 350 drug poses generated and docked on different docking methods. In the PDB method a total of 51 poses were docked on the site in which pose number 3 and pose number 4 showed good interaction with the least energy complex(PDB(P3, P4)). In the RC method, 14 sites were generated and 105 drug poses were generated and docked on only six sites. The least energy with good interaction showed with pose number 4 and 9 on the first site (RC (S1, P4), (S1, P9)). In the direct method, a total of 100 drug poses were generated and docked. The good interaction is shown with pose number 5(DIRECT (P5)). Ninety-four drug poses were generated and docked in the motif-based method, and the least energy with good interaction showed with pose number 1(MOTIF (P1)).

Docking of Temozolomide drug with 2XP2 protein, total 99 drug poses generated and docked on different docking methods. In the PDB method a total of 51 drug poses generated and docked in which drug pose number 3 with complex formed shows least energy with good interaction (PDB (P3)). Ten sites were generated in the
RC method, and 40 poses were docked on six sites. The least energy showed complex with good interactions got on pose number 2 and posed number 4 formed complexes only on first site (RC(S1, P2)(S1, P4)). In the direct method a total of five poses were generated and docked on the site. The least energy and good interaction showed complex was pose number 3(DIRECT (P3)). In the motifbased method, only three poses generated and docked in which pose number 2 with protein complex shows the least energy with good interaction on the site (MOTIF (P2)).

From the result table of the Temozolomide drug with proteins, we only select two sets of data. Temozolomide drug interaction with already reported amino acid residues of C-MET, C-ROS1 and ALK. Moreover, the Temozolomide drug interaction with known methylation sites of the proteins. Based on the drug properties and least complex energy, we selected only the best complex from various docking methods of Crizotinib and Temozolomide with each protein, shown in Tables 6 and 7.

The results in Tables 6 and 7 contain docking score, binding energy, least complex energy of both Crizotinib and Temozolomide drug with protein in each method. And also the main hydrogen bond interaction showed amino acid residues with each drug at the binding sites in all the docking.

When we looked at the final docking result, we understood that the energy of the Temozolomide bound 
Table 6 Docking result of a best-docked complex of Crizotinib drug with C-MET, C-ROS1 and ALK proteins

\begin{tabular}{llllll}
\hline Protein name & Type of docking & Docking score & $\begin{array}{l}\text { Binding energy } \\
\text { (kcal/mol) }\end{array}$ & $\begin{array}{l}\text { Complex energy } \\
\text { (kcal/mol) }\end{array}$ & Interacting residues \\
\hline DRUG-CRIZOTINIB & & & & & \\
2WGJ & PDB(P6) & 139.105 & -44.1433 & $-11,179.9569$ & PRO1158, MET1160 \\
3ZBF & MOTIF(P1) & 114.545 & -112.0438 & $-11,514.2552$ & ASP2033,GLU2027,MET2029 \\
$2 X P 2$ & RC(S1,P8) & 108.615 & -189.7012 & $-11,666.7948$ & GLU1197, MET1199 \\
\hline
\end{tabular}

Table 7 Docking results of a best-docked complex of Temozolomide drug with C-MET, C-ROS1 and ALK proteins

\begin{tabular}{|c|c|c|c|c|c|}
\hline Protein name and drug name & Type of docking & Docking score & $\begin{array}{l}\text { Binding energy } \\
\text { (kcal/mol) }\end{array}$ & $\begin{array}{l}\text { Complex energy } \\
\text { (kcal/mol) }\end{array}$ & Interacting residues \\
\hline \multirow[t]{2}{*}{ 2WGJ } & PDB(P9) & 72.1914 & 7.4427 & $-11,266.0096$ & ARG1208 \\
\hline & PDB(P4) & 74.4989 & -16.3492 & $-11,289.7872$ & MET1160 \\
\hline \multirow[t]{5}{*}{ DRUG-TEMOZOLOMIDE } & $\mathrm{RC}(\mathrm{S} 1, \mathrm{P} 6)$ & 65.8739 & 20.7625 & $-11,295.5088$ & ARG1227, GLU1127 \\
\hline & $\mathrm{RC}(\mathrm{S} 1, \mathrm{P} 4)$ & 67.5009 & -25.2079 & $-11,302.4869$ & ARG1227 \\
\hline & DIRECT(P4) & 68.0813 & -27.8584 & $-11,305.0830$ & PRO1158, MET1160 \\
\hline & MOTIF(P1) & 74.7354 & -32.2530 & $-11,309.5066$ & ARG1208 \\
\hline & MOTIF(P11) & 56.0548 & -19.8256 & $-11,292.9200$ & PRO1158, MET1160 \\
\hline \multirow[t]{2}{*}{$3 Z B F$} & PDB(P3) & 60.5055 & -21.2784 & $-11,597.8$ & LYS1980,ARG2083 \\
\hline & PDB(P4) & 58.5464 & -40.5732 & $-11,659.6814$ & MET2029,GLU2027 \\
\hline \multirow[t]{2}{*}{ DRUG-TEMOZOLOMIDE } & $\mathrm{S} 1(\mathrm{P} 9)$ & 51.9164 & -38.8334 & $-11,657.6084$ & LYS1980 \\
\hline & DIRECT(P5) & 56.4637 & -12.0296 & $-11,627.0789$ & GLU2027,MET2029 \\
\hline $2 X P 2$ & $\mathrm{PDB}(\mathrm{P} 3)$ & 61.6198 & -3.4005 & $-11,693.1778$ & GLU1197,MET1199 \\
\hline \multirow[t]{4}{*}{ DRUG-TEMOZOLOMIDE } & $\mathrm{RC}(\mathrm{S} 1, \mathrm{P} 2)$ & 60.1738 & -44.4725 & $-11,734.7565$ & $\begin{array}{l}\text { ARG1275, ASP1160, } \\
\text { GLU1167 }\end{array}$ \\
\hline & $\mathrm{RC}(\mathrm{S} 1, \mathrm{P} 4)$ & -59.7869 & -59.7869 & $-11,750.1009$ & LYS1150,ARG1275 \\
\hline & DIRECT(P3) & 61.0851 & -25.9935 & $-11,715.3869$ & MET1199 \\
\hline & MOTIF(P2) & 52.4923 & -27.8563 & $-11,717.0798$ & LYS1150,ASP1249,ASP1270 \\
\hline
\end{tabular}

protein complexes is very less. This means that the complex will be more stable. A docked complex's CE indicates the overall energy attained after the drug is bound on the protein surface. This is the sum of ligand energy, protein energy and binding energy. To confirm stability and understand the molecules' behavior of docked complex in a biological system, we should do molecular dynamics (MD) simulation study. To find out more stable complex from the Temozolomide drug protein bounded protein complex, we consider the most least energy complex from all the method of C-MET, C-ROS1 and ALK protein complexes and performed MD simulation based on the order of their least energy.

To understand ligand bounded protein structural deviations and fluctuations, we selected both ligand-free protein and ligand bounded of C-MET, C-ROS1 and ALK proteins structures for MD simulation.

\section{Dynamic simulation result}

In the docking studies, we identified that the Temozolomide drug bounded protein complex showed the least complex energy in all the methods. So in the MD simulation analysis, we selected the Temozolomide drug bounded protein complexes of C-MET, C-ROS1 and ALK structures based on the order of least energy. To maintain a stable and accurate nature of MD simulations, we run the MD simulation at $200 \mathrm{ps}$ and the constant temperature fluctuations at $300 \mathrm{~K}$ in all the protein complexes based on the Discovery Studio Standard Dynamic Cascade procedure (Ref: user manual of Simulation protocol in Discovery Studio Tool).

In the MD simulation study, we first considered the protein docked complex was C-MET (2WGJ). A total of seven complex structures were filtered from all the four docking methods of C-MET protein with the Temozolomide drug, listed in Table 7. From these seven protein docked complexes of C-MET protein, first, we selected MOTIF (P1) of 2WGJ protein docked complex for MD simulation based on their least complex energy. In this complex, the amino acid residue ARG1208 with the Temozolomide drug showed a strong hydrogen bond at the protein's binding site. After the MD simulation run, 
we could identify that this hydrogen bond interaction has no conformational stability in the biological condition, and the bond-breaking occurred. So we considered the next least energy docked complex, site-specific/DIRECT (P4) of 2WGJ for MD simulation. This docked complex showed strong hydrogen bond interaction at the amino acid residues PRO1158, MET1160 with Temozolomide drug at the binding site. After the MD simulation run, we checked the hydrogen bond interaction at the protein's binding site. We found that the same hydrogen bond interaction between the amino acid resides PRO1158, MET1160, and the Temozolomide drug in the protein complex. After the MD run, we performed analyzed the trajectory to understand the protein complex's RMSD and RMSF.

Next, we performed the PDB (P4) of the $3 \mathrm{ZBF}(\mathrm{C}-\mathrm{ROS} 1)$ complex for MD simulation based on the least energy. In this complex, the hydrogen bond formed between Temozolomide drug pose with MET2029 and GLU2027 amino acid residues at the protein's binding site. After the MD simulation run, we checked the hydrogen bond interaction at the binding site of the protein complex. Then, we could identify that this complex attained a stable conformation throughout the MD run and kept the hydrogen bond between the Temozolomide drug with the amino acid residues MET2029, GLU2027 at the binding sites. Based on this result, we analyzed the docked complex's trajectory to calculate the RMSD and RMSF. However, in the RC (S1, P4) complex of 2XP2 (ALK) MD simulation, we found bond breaking in hydrogen bond interaction at the amino acid residues LYS1150, ARG1275 with Temozolomide drug. So we selected the next least energy complex of RC (S1, P2) of 2XP2 and again performed an MD simulation run. In this docked complex, the hydrogen bond formed between amino acid residues ARG1275, ASP1160, GLU1167 and Temozolomide drug. After MD simulation, we could find that this complex was a stable complex at this hydrogen bond interaction. Then, we performed trajectory analysis on this complex to calculate the RMSD and RMSF. From this MD run, we selected the best three docked complexes of C-MET, C-ROS1 and ALK protein complexes based on the least complex energy and conformational stability, which are shown in Table 8.

We performed MD simulation analysis on ligand-free protein structure of C-MET, C-ROS1 and ALK protein to understand actual conformational changes of docked proteins C-MET, C-ROS1 and ALK. From the MD simulation analysis of best-docked complexes of Temozolomide drug with proteins, we got the average potential energy of C-MET (2WGJ (DIRECT (P4))) complex was -66,117.6, and C-ROS1 (3ZBF (PDB (P4)), ALK (2XP2 (S1, P2)) proteins complex were $-96,712.009$, $-80,334.651$, respectively. In the MD simulation of ligand-free protein structure of C-MET, C-ROS1 and ALK, we got the average potential energy of C-MET protein was-66303 and the C-ROS1 and ALK protein were $-94,171,-78,997$.

From the RMSD value, we can understand that overall protein conformational changes (Structural deviations) [31] happened from its original structure when a drug molecule is bound on its protein surface and understands the optimized states of ligand bounded protein structures. Usually, an optimized protein structure RMSD value should be less than $1.5 \AA$, which is considered a good structure. Here RMSD value is generated for 100 docked protein conformations based on 224-ps time interval, which is mentioned in Figs. 3, 4 and 5. From the RMSD graph of C-MET protein complex, we can understand a small hike in the conformations during the time interval of 36-46 ps. Apart from this region, the protein conformations at all other time intervals were at optimized condition, and the RMSD values were below $1.5 \AA$. Look at the original structure and ligand bounded protein structure, and it is understood that there was a small deviation that occurred only in the ligand bounded protein structure. In the case of C-ROS1 protein, the RMSD value is always less than 1.4 $\AA$ in all conformations. But in ALK protein, there is a small deviation between 26- and 80-ps

Table 8 Details of best-docked complexes of proteins with least energy and main hydrogen bond interaction showed amino acid residues on the binding sites

\begin{tabular}{|c|c|c|c|c|c|}
\hline Protein name and drug name & Type of docking & Docking score & $\begin{array}{l}\text { Binding energy } \\
\text { (kcal/mol) }\end{array}$ & $\begin{array}{l}\text { Complex energy } \\
\text { (kcal/mol) }\end{array}$ & Interacting residues \\
\hline $\begin{array}{l}\text { Protein: } 2 W G J \\
\text { DRUG-TEMOZOLOMIDE }\end{array}$ & DIRECT(P4) & 68.0813 & -27.8584 & $-11,305.0830$ & PRO1158, MET1160 \\
\hline $\begin{array}{l}\text { Protein: 3ZBF } \\
\text { DRUG-TEMOZOLOMIDE }\end{array}$ & PDB(P4) & 58.5464 & -40.5732 & $-11,659.6814$ & MET2029, GLU2027 \\
\hline $\begin{array}{l}\text { Protein: } 2 \text { XP2 } \\
\text { DRUG- } \\
\text { TEMOZOLOMIDE }\end{array}$ & $\mathrm{RC}(\mathrm{S} 1, \mathrm{P} 2)$ & 60.1738 & -44.4725 & $-11,734.7565$ & ARG1275, ASP1160, GLU1167 \\
\hline
\end{tabular}




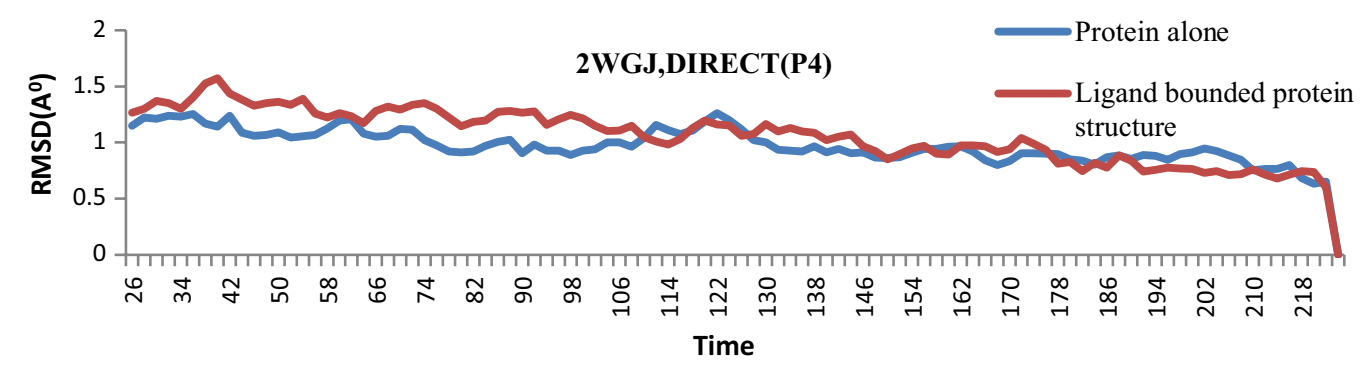

Fig. 3 RMSD graph of ligand-free protein and ligand bounded protein complex of C-MET protein

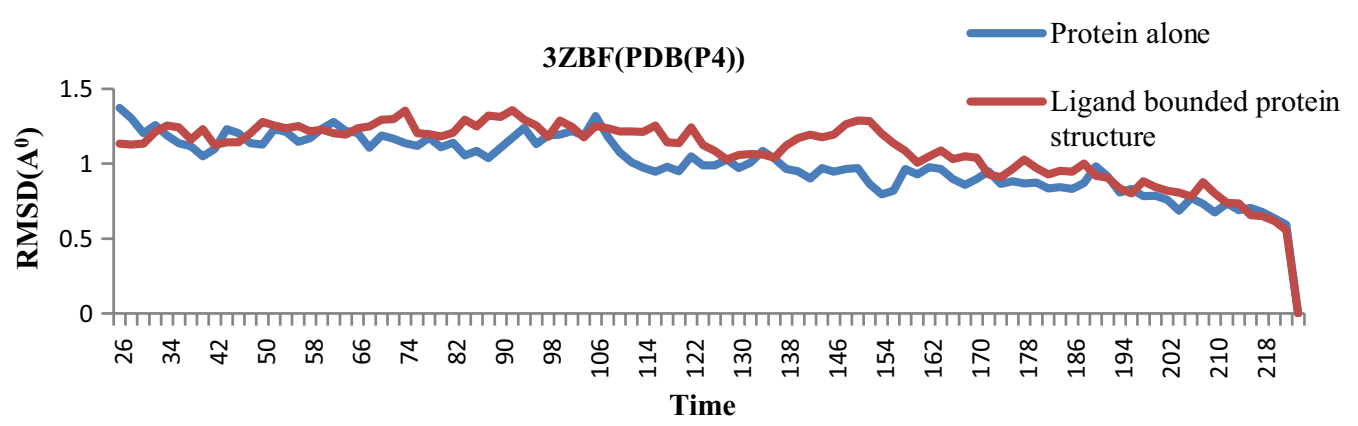

Fig. 4 RMSD graph of ligand-free protein and ligand bounded protein complex of C-ROS1 protein

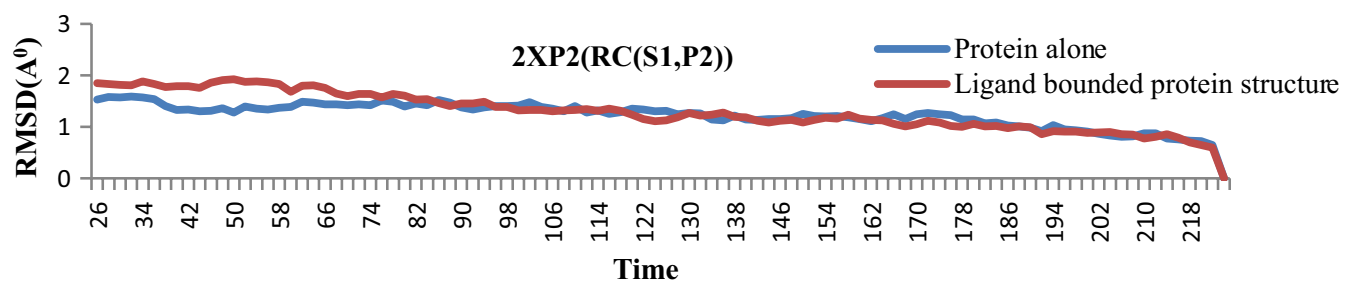

Fig. 5 RMSD graph of ligand-free protein and ligand bounded protein complex of ALK protein

time interval where RMSD went above $1.5 \AA$. However, after at a certain time intervals, it keeps the RMSD value below $1.5 \AA$. The average RMSD values of C-MET, C-ROS1 and ALK docked complexes were $1.05879,1.05879$ and 1.29505 , respectively, and also all three complexes showed a stable conformation when it reached at $224 \mathrm{ps}$. In the case of ligand-free protein structure of C-MET, C-ROS1 and ALK, we got the average RMSD value were $0.966915,0.996956$ and 1.22515 , respectively.

RMSD graphs of C-MET, C-ROS1 and ALK of both ligands bounded and ligand-free proteins structures are shown in Figs. 3, 4 and 5.

RMSF value is used to measure the ratio of protein structures' overall flexibility $[30,32]$, by fluctuations occurring in each amino acid residues of protein structure when a ligand is bound on a protein surface. The most acceptable range of RMSF value is below $2.25 \AA$. Usually, terminal residues and loop regions residues have more chances for fluctuations, but movements are more restricted in middle regions. In C-MET protein, there is a higher residual fluctuation in the loop region between residues HIS 1088 and LEU1112. Apart from this region overall ratio of RMSF values comes under below $2 \AA$. And also, there is a small fluctuation occurred in the region PRO1158 and MET1160. But this fluctuation was below the acceptable value. But in the case of C-ROS1 ligand-free protein, there are two terminal residual fluctuations above $2.25 \AA$ already have, and the remaining fluctuation ratio was below $2.25 \AA$. 
But we look at the ligand bounded protein structure, we can see that only the left side terminal has fluctuation above $2.25 \AA$, but the rightmost terminal portion fluctuations are below $2.25 \AA$. In the hydrogen bond region of MET2029, GLU2027 residues, a slight degree of fluctuations occurred to down compared to the original structure, and that states may affect the protein's overall flexibility. In ALK protein, hydrogen bond interaction on ARG1275 and GLU1167 shows no fluctuation occurred in this region. However, in the surrounding regions, there was a greater degree of fluctuations above $2.25 \AA$. The higher degree of fluctuations occurred in ASN1093-SER1106, GLU1132-LEU1145, GLU1210-ASP1225 and ASN1394, respectively, and the remaining amino acid residues fluctuations below $2.25 \AA$. The RMSF graphs of ligand-free proteins and ligand bounded proteins of C-MET, C-ROS1 and ALK are shown in Figs. 6, 7 and 8.
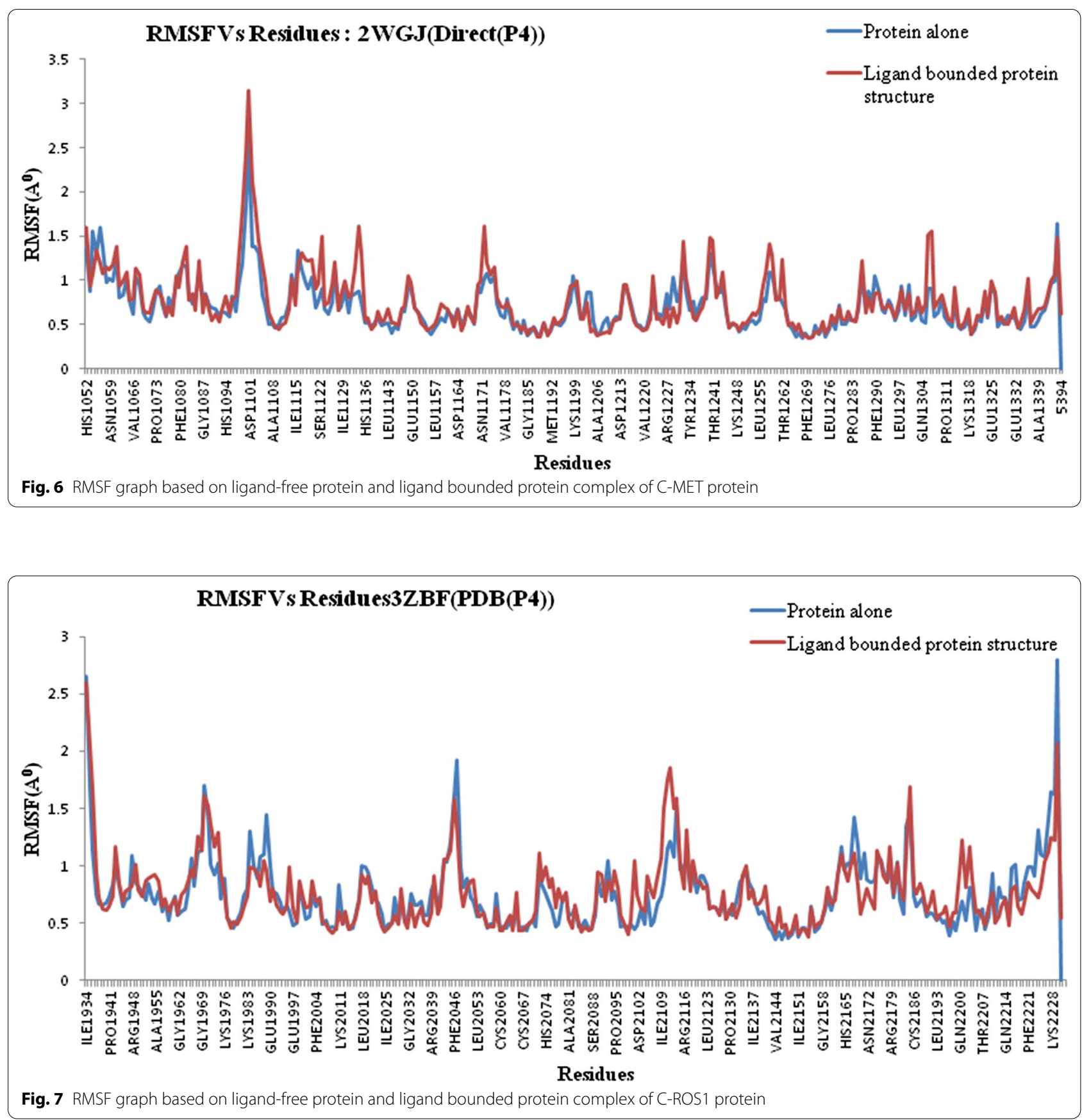


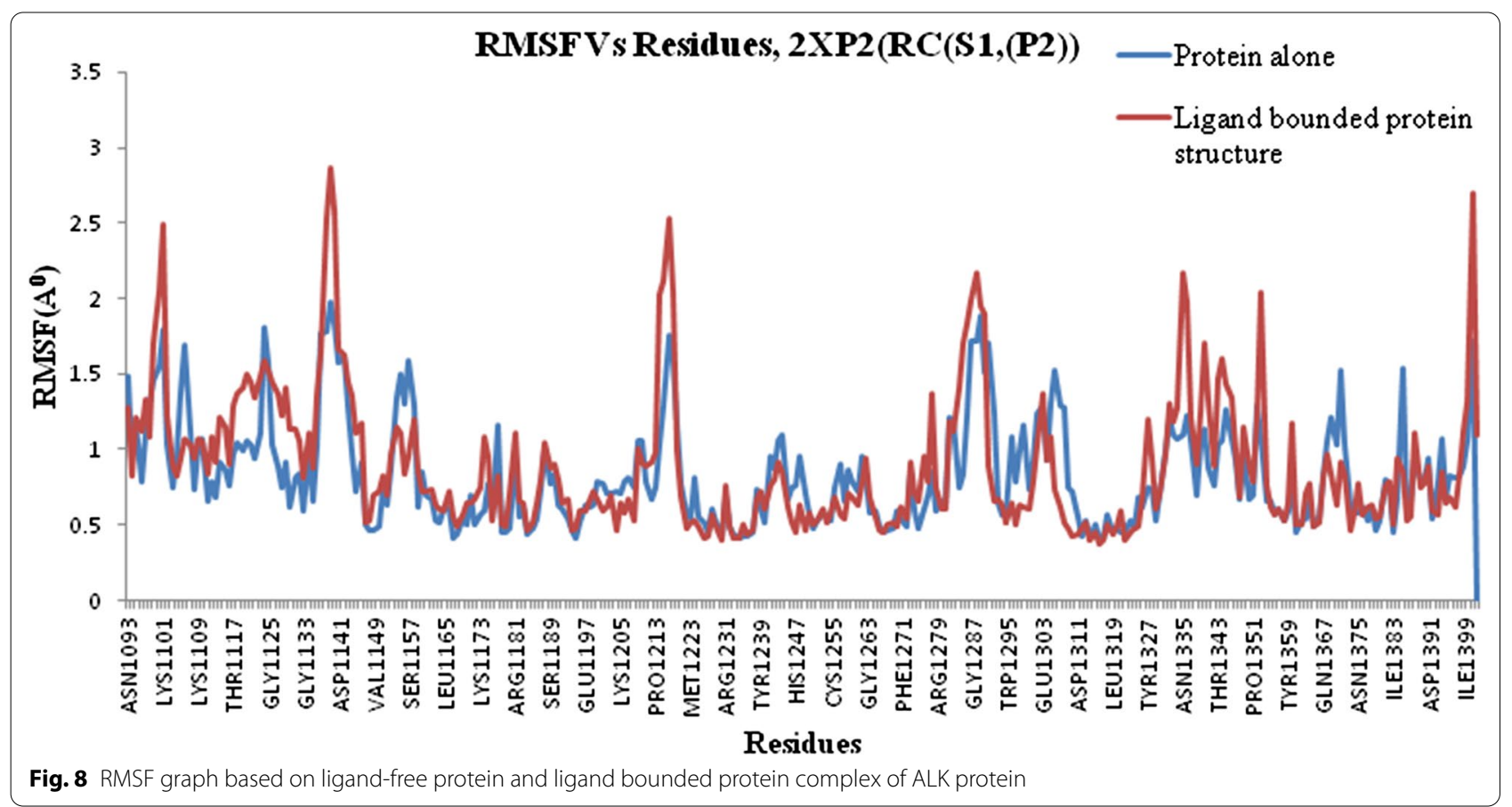

\section{The structure analysis details of C-MET, C-ROS1 and ALK protein with Temozolomide drug in docking}

The detailed intermolecular interactions at the binding site of Temozolomide drug with proteins C-MET, C-ROS1 and ALK are shown in Table 9. We could identify two types of noncovalent bond interaction at the protein's binding site of C-MET (2WGJ) with Temozolomide drug, which is shown in Table 9. The main noncovalent bond interaction found on the active site was two hydrogen bond and nine hydrophobic interactions. The two hydrogen bond interaction includes one conventional hydrogen bond (MET1160) and one carbon-hydrogen bond interaction (PRO1158). The nine hydrophobic interactions include one Pi-Pi stacked interaction (TYR1159), six Pi-Alkyl interactions (VAL1092, MET1211 ("2times), MET1160, ALA1108 ("2times)) and two Alkyl interactions (ALA1226, LEU1157).

In the C-ROS1 (3ZBF) protein with Temozolomide drug interaction, we found hydrogen bond and hydrophobic interaction at the binding site. The hydrogen bond interaction includes one conventional hydrogen bond interaction (MET2029) and one carbon-hydrogen bond interaction (GLU2027) and nine hydrophobic interaction, which includes three alkyl interactions (LEU2010, LEU2026, LEU2086), six Pi-alkyl interactions (VAL1959, ALA1978("2times), LEU2086("3times)).

The main noncovalent bond interactions found on the ALK (2XP2) protein's active site with Temozolomide drug were eight hydrogen bonds and one electrostatic interaction. The hydrogen bond interaction includes five conventional hydrogen bond interactions (ARG1275 ("3times), GLU1167, ASP1160) and three carbon-hydrogen bond interactions (ASP1160 ("2times), ASP1276), and also one electrostatic interaction (ASP1163).

Figures 9, 10 and 11 represent the best-docked protein complex details of C-MET, C-ROS1 and ALK. The square box colors indicate that the type of interaction obtained between each amino acid residue and drug in the protein's binding sites is shown in the 2D diagram. Here four types of images are shown. Image (a) represents the 2D interaction view at the binding site, images (b) and (c) represent the surface view of hydrophobic and hydrogen bond interaction of the protein complex at each binding site, and image (d) represents the full view of the docked protein complex.

\section{Discussion}

The proposed work is a comparative analysis study of two chemotherapy drugs Crizotinib and Temozolomide, to identify which drug is more effective in treating GBM and NSCLC when both the drugs are used as target chemotherapy drugs for these cancers. For this, we performed docking studies in the target proteins of C-MET, C-ROS1 and ALK of GBM and NSCLC with the drugs Crizotinib and Temozolomide. Here four different docking methods had been used to identify the druggable binding site of the proteins. The final docking result was evaluated based on MD simulation 
Table 9 Details of intermolecular interactions at the binding site of Temozolomide drug with proteins C-MET, C-ROS1 and ALK

\begin{tabular}{|c|c|c|c|c|c|}
\hline $\begin{array}{l}\text { Protein } \\
\text { Name }\end{array}$ & $\begin{array}{l}\text { Name of the site and } \\
\text { pose number }\end{array}$ & Type of interaction & Category & $\begin{array}{l}\text { The interacting amino acid in the } \\
\text { binding site with Temozolomide drug }\end{array}$ & Distance \\
\hline \multirow[t]{5}{*}{ 2WGJ } & \multirow[t]{5}{*}{ DIRECT(P4) } & Conventional hydrogen bond & Hydrogen bond & 5394:H16:A: MET1160:O & 2.24481 \\
\hline & & Carbon hydrogen bond & Hydrogen bond & 5394:H17A: PRO1158:O & 2.45839 \\
\hline & & Pi-Pi stacked & Hydrophobic & :5394—A:TYR1159 & 4.93012 \\
\hline & & Pi-alkyl & Hydrophobic & $\begin{array}{l}: 5394-A: V A L 1092 \\
: 5394 \text { A:MET1211 } \\
: 5394 \text {-A:MET1211 } \\
: 5394 \text { A:MET1160 } \\
: 5394 \text {-A:ALA11 108 } \\
: 5394 \text { A:ALA1108 }\end{array}$ & $\begin{array}{l}4.83973 \\
3.91876 \\
3.77984 \\
5.1382 \\
4.89055 \\
4.93458\end{array}$ \\
\hline & & Alkyl & Hydrophobic & $\begin{array}{l}\text { A:ALA1226:5394:C13 } \\
: 5394: C 13: A: L E U 1157\end{array}$ & $\begin{array}{l}4.39785 \\
4.69299\end{array}$ \\
\hline \multirow[t]{4}{*}{$3 Z B F$} & \multirow[t]{4}{*}{$\mathrm{PDB}(\mathrm{P} 4)$} & Conventional hydrogen bond & Hydrogen bond & 5394:H16:A:MET2029:O & 2.42253 \\
\hline & & Carbon hydrogen bond & Hydrogen bond & 5394:H17-A:GLU2027:O & 2.32972 \\
\hline & & Alkyl & Hydrophobic & $\begin{array}{l}\text { 5394:C13-A:LEU2010 } \\
\text { 5394:C13—A:LEU2026 } \\
\text { 5394:C13—A:LEU2086 }\end{array}$ & $\begin{array}{l}5.45684 \\
4.55133 \\
5.3763\end{array}$ \\
\hline & & Pi-alkyl & Hydrophobic & $\begin{array}{l}\text { 5394-A:VAL1959 } \\
\text { 5394—A:ALA1978 } \\
\text { 5394-A:ALA1978 } \\
\text { 5394—A:LEU2028 } \\
\text { 5394—A:LEU2086 } \\
\text { 5394—A:LEU2086 }\end{array}$ & $\begin{array}{l}5.24465 \\
4.34067 \\
3.69966 \\
5.1594 \\
4.34929 \\
4.68103\end{array}$ \\
\hline \multirow[t]{3}{*}{$2 \times P 2$} & \multirow[t]{3}{*}{$\mathrm{RC}(\mathrm{S} 1, \mathrm{P} 2)$} & Conventional hydrogen bond & Hydrogen bond & $\begin{array}{l}\text { A:ARG1275:HH12-5394:O2 } \\
\text { A:ARG1275:HH22-5394:O2 } \\
\text { A:ARG1275:HH22-5394:N6 } \\
\text { 5394:H15-A:GLU1167:OE2 } \\
\text { 5394:H16-A:ASP1 160:O }\end{array}$ & $\begin{array}{l}2.24837 \\
2.41096 \\
2.23388 \\
2.94087 \\
2.61508\end{array}$ \\
\hline & & Carbon hydrogen bond & Hydrogen bond & $\begin{array}{l}\text { A:ASP1 160:HA_5394:N5 } \\
\text { 5394:H17- A:ASP1160:OD1 } \\
\text { 5394:H18- A:ASP1276:OD2 }\end{array}$ & $\begin{array}{l}2.73974 \\
2.25332 \\
2.33541\end{array}$ \\
\hline & & Pi-anion & Electrostatic & A:ASP1163:OD2-5394 & 3.68967 \\
\hline
\end{tabular}

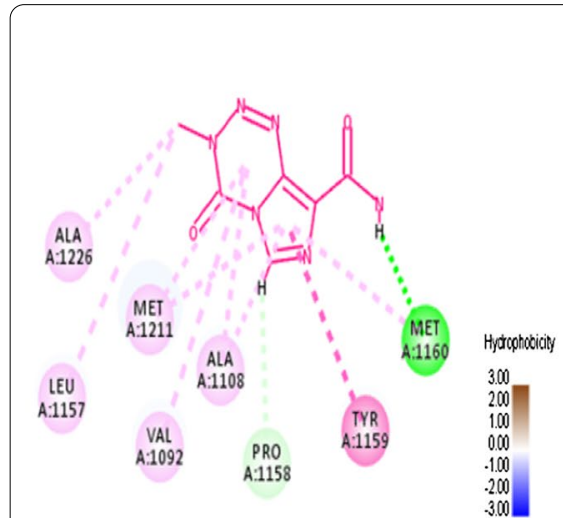

(a)

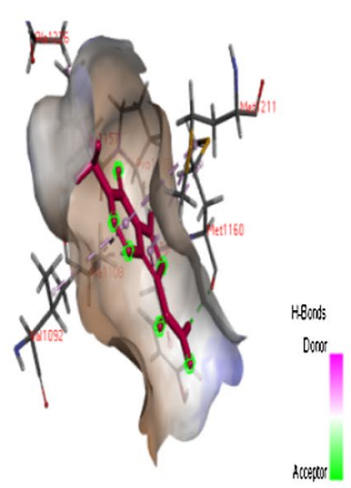

(b)

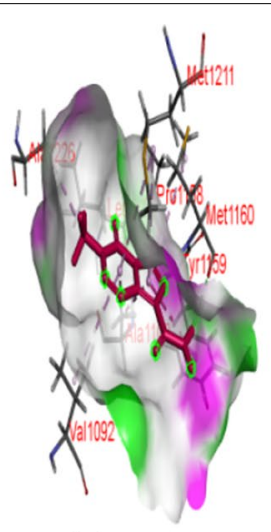

(c)

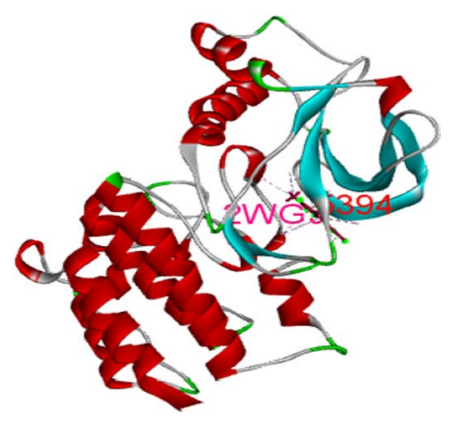

(d)

Interactions

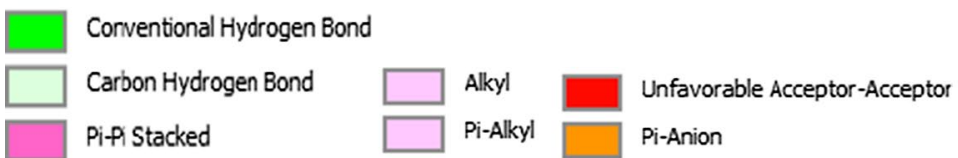

Fig. $92 \mathrm{D}$ and 3D interaction images of drug Temozolomide at the binding sites of protein C-MET (2WGJ: DIRECT (P4)) 


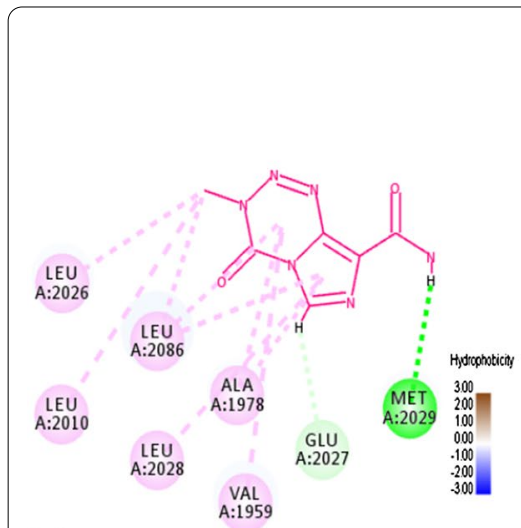

(a)

\section{Interactions}

Corventional Hydrogen Bond

Carbon Hydrogen Bond

Pifi Stacked

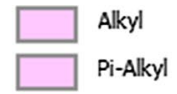

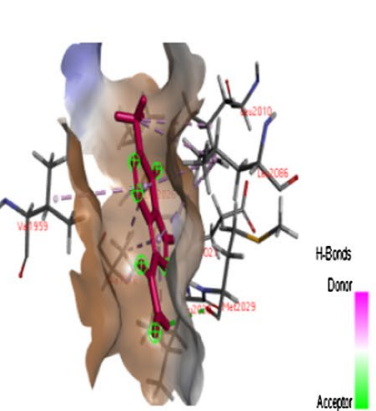

(b)

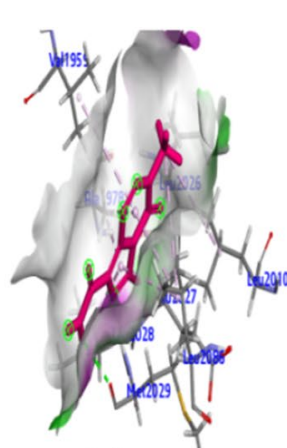

(c)

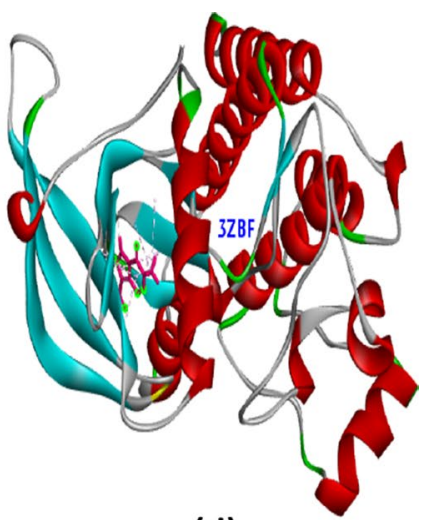

(d)

Fig. 10 2D and 3D interaction images of drug Temozolomide at the binding sites of protein C-ROS1 (3ZBF: PDB (P4))

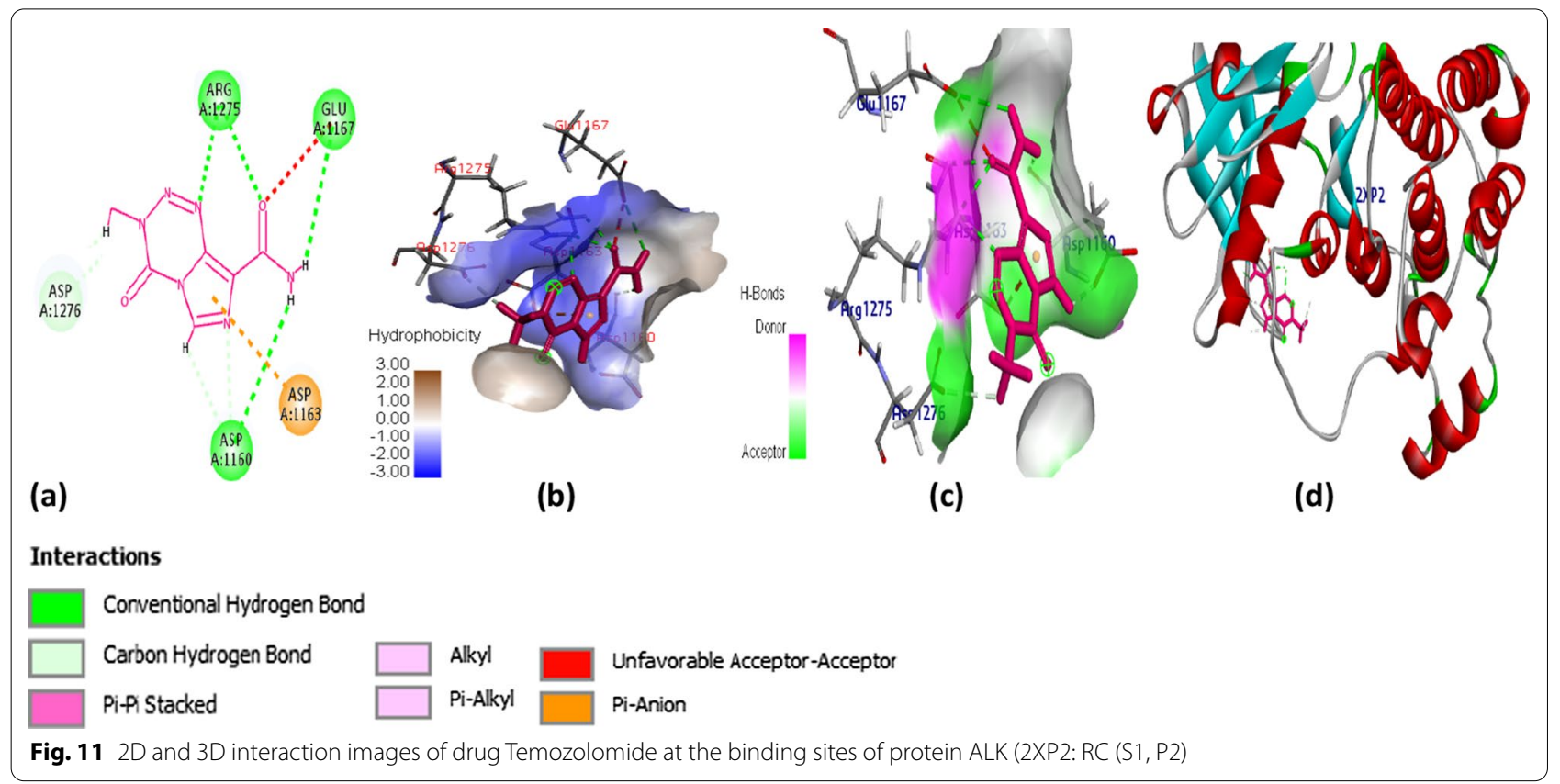

analysis followed by drug properties and the complex energy of the docked complex. We got the least energy complex in C-MET (2WGJ) protein when Temozolomide and Crizotinib were bounded on the same amino acid residues MET1160, PRO1158. The x-ray crystallographic studies by the Crizotinib drug with C-MET protein reveal that these two amino acid residues are the ATP binding sites of C-MET protein [14]. The final evaluation of better drugs was identified by least energy of the docked complexes. Moreover, the stability of the docked complex was determined by MD simulation analysis. From the final docking result of Crizotinib and Temozolomide bounded protein structure of C-MET, we could understand that the least energy of both the drug complexes was $-11,305.0830$ (Temozolomide complex: 2WGJ (Direct (P4))) and - 11,179.9569 
(Crizotinib complex: 2WGJ (PDB (P6))). Based on the least energy, we performed the MD simulation run with the Temozolomide bounded docked complex. After MD simulation analysis, we found that the Temozolomide drug showed the same hydrogen bond interaction with the amino acid residues MET1160, PRO1158 at the binding site of C-MET protein (Temozolomide complex: 2WGJ (Direct (P4))) and also the C-MET docked complex was more stable on this interaction.

The docking study of Crizotinib and Temozolomide with C-ROS1 (3ZBF) proteins reveals that the drug's binding to MET2029, GLU2027 amino acid residues gave the least complex energy. It also reported that these two amino acid residues are the ATP binding sites of C-MET protein [15]. In C-ROS1 protein, the least energy of both the complex was -11,659.6814 (Temozolomide complex: 3ZBF (PDB (P4))) and - 11,514.2552 (Crizotinib bounded complex: 3ZBF (Motif (P1))). Based on the least energy, we performed an MD simulation run on the C-ROS1 docked complex (Temozolomide complex: 3ZBF (PDB (P4))). From this study, we identified that the hydrogen bond interaction of the Temozolomide drug with the amino acid residues MET2029, GLU2027 was strong, and the overall docked complex attained a stable conformation on these interactions.

In ALK (2XP2) protein, the least energy attained complexes were formed when the drug Crizotinib binds on the GLU1197 and MET1199 amino acid residues and Temozolomide drug binds on the amino acid residues ARG1275, ASP1160, GLU1167 in the protein. The energy of the docked complex was $-11,734.7565$ (Temozolomide: 2XP2 (RC (S1, P2))) and - 11,656.9972 (Crizotinib: 2XP2 (MOTIF (P9))). In ALK protein, Crizotinib drug bound on the already reported binding regions of GLU1197 and MET1199 residues [14]. The drug Temozolomide bound on the ALK protein at the methylation sites of ARG1275, ASP1160, GLU1167 [24-28, 33]. After the MD simulation, we could understand that the Temozolomide drug showed strong hydrogen bond interaction with the amino acid resides ARG1275, ASP1160, and GLU1167 at the binding site of ALK protein, and the docked complex attained a stable conformation on these hydrogen bond interactions.

From the proposed work, we could confirm that the Temozolomide drug bounded protein complex of C-MET, C-ROS1 and ALK showed the least complex energy. The less energy complex indicates that the complex is more stable, and the drug can produce better efficacy since it binds on these protein binding sites more time. So Temozolomide drug can produce more drug efficacy than Crizotinib in the treatment of GBM and NSCLC.

\section{Conclusion}

Intermolecular level interaction studies are beneficial to understand the in-depth activities of drugs and proteins. We cannot find a generalized solution for understanding the complete functionality of the drug when it binds to a protein surface. However, we can extract some set of useful information from this type of intermolecular level analysis. Here we tried to perform a comparative in silico analysis study of Crizotinib and Temozolomide drug with proteins based on drug properties and complex energy. Moreover, the final result is extracted based on the least complex energy (CE) of the docked complex. In the docking study, we usually focus on the docking score of a top drug pose and its binding energy. From our study, we saw that this type of docked complex shows very high complex energy. That means when a drug binds on a protein surface with a good docking score and binding energy, that complex often will be unstable and will not exhibit the desired effect of drugs properly in the diseased pathway. Also, Temozolomide drug activities in C-MET, C-ROS1 and ALK target proteins of GBM and NSCLC are not reported so far. The current method provides a better understanding of the intermolecular level interaction of Temozolomide drug with protein in targeted based treatment strategy and also the effectiveness of Crizotinib and Temozolomide at the protein level. Based on the result, it is identified that the Temozolomide drug's alkylation is more potent than the inhibition of Crizotinib drug in the diseased pathway of GBM and NSCLC.

\section{Abbreviations}

WHO: World Health Organization; GBM: Glioblastoma Multiforme; NSCLC: Non-small-cell lung carcinoma; RTKs: Receptor tyrosine kinases; CE: Complex energy; RC: Receptor Cavity; MD: Molecular Dynamics; RMSD: Root mean square deviation; RMSF: Root mean square fluctuation.

\section{Acknowledgements}

We would like to thanks the University of Kerala, the State Interuniversity Center of Excellence in Bioinformatics (SIUCE, Govt. of Kerala), Department of Biotechnology (DBT-BIF project), Govt. of India, for providing all the facility for done this work.

\section{Authors' contributions}

SY performed all the research activities, VC and ASN monitored the research work and SY and VC and ASN participated in preparing and drafting the manuscript. All authors read and approved the final manuscript.

\section{Funding}

No funding was received.

\section{Availability of data and materials}

All necessary data generated or analyzed during this study are included in this article. Any additional data could be available from the corresponding author upon request. 


\section{Declarations}

Ethics approval and consent to participate

Not applicable.

\section{Consent for publication}

Not applicable.

\section{Competing interests}

The authors declare that they have no competing interests.

\section{Author details}

${ }^{1}$ Department of Computational Biology and Bioinformatics, University of Kerala, Kariavattom Campus, Trivandrum, Kerala 695581, India. ${ }^{2}$ Department of Computer Science, University of Kerala, Trivandrum 695581, India.

\section{Received: 17 March 2021 Accepted: 22 August 2021}

\section{Published online: 08 September 2021}

\section{References}

1. Hanif F, Muzaffar K, Perveen K, Malhi SM, Simjee SU (2017) Glioblastoma multiforme: a review of its epidemiology and pathogenesis through clinical presentation and treatment. Asian Pac J Cancer Prev APJCP 18(1):3

2. Pikor LA, Ramnarine VR, Lam S, Lam WL (2013) Genetic alterations defining NSCLC subtypes and their therapeutic implications. Lung Cancer 82(2):179-189

3. Oguz A, Unal D, Kurtul N, Aykas F, Mutlu H, Karagoz H, Cetinkaya A (2013) Season of diagnosis and survival of advanced lung cancer cases-any correlation? Asian Pac J Cancer Prev 14(7):4325-4328

4. Du Z, Lovly CM (2018) Mechanisms of receptor tyrosine kinase activation in cancer. Mol Cancer 17(1):58

5. Davies KD, Doebele RC (2013) Molecular pathways: ROS1 fusion proteins in cancer. Clin Cancer Res 19(15):4040-4045

6. Sierra JR, Tsao M-S (2011) C-MET as a potential therapeutic target and biomarker in cancer. Therap Adv Med Oncol. https://doi.org/10.1177/ 1758834011422557

7. Aubry A, Galiacy S, Allouche M (2019) Targeting ALK in cancer: therapeutic potential of proapoptotic peptides. Cancers (Basel) 11(3):275. https:// doi.org/10.3390/cancers11030275

8. Minniti G, Muni R, Lanzetta G, Marchetti P, Enrici RM (2009) Chemotherapy for glioblastoma: current treatment and future perspectives for cytotoxic and targeted agents. Anti-cancer Res 29(12):5171-5184

9. Adonizio CS, Babb JS, Maiale C, Huang C, Donahue J, Millenson MM, Langer CJ (2002) Temozolomide in non-small-cell lung cancer: preliminary results of a phase II trial in previously treated patients. Clin Lung Cancer 3(4):254-258

10. Chen RL, Zhao J, Zhang XC, Lou NN, Chen HJ, Yang X, Zhong WZ (2018) Crizotinib in advanced non-small-cell lung cancer with concomitant ALK rearrangement and C-MET over expression. BMC Cancer 18(1):1171

11. Le Rhun E, Chamberlain MC, Zairi F, Delmaire C, Idbaih A, Renaud F, Grégoire V (2015) Patterns of response to Crizotinib in recurrent glioblastoma according to ALK and MET molecular profile in two patients. CNS oncology 4(6):381-386

12. Das A, Cheng RR, Hilbert ML, Dixon-Moh YN, Decandio M, Vandergrift WA 3rd, Banik NL, Lindhorst SM, Cachia D, Varma AK, Patel SJ, Giglio P (2015) Synergistic effects of crizotinib and temozolomide in experimental FIGROS1 fusion-positive glioblastoma. Cancer Growth Metastasis 8:51-60. https://doi.org/10.4137/CGM.S32801

13. Meng XY, Zhang HX, Mezei M, Cui M (2011) Molecular docking: a powerful approach for structure-based drug discovery. Curr Comput Aided Drug Des 7(2):146-157. https://doi.org/10.2174/157340911795677602

14. Cui JJ, Tran-Dubé M, Shen H, Nambu M, Kung PP, Pairish M, McTigue M (2011) Structure based drug design of Crizotinib (PF-02341066), a potent and selective dual inhibitor of mesenchymal-epithelial transition factor (C-MET) kinase and anaplastic lymphoma kinase (ALK). J Med Chem 54(18):6342-6363
15. Awad MM, Katayama R, McTigue M, Liu W, Deng YL, Brooun A, Wilner KD (2013) Acquired resistance to Crizotinib from a mutation in CD74-ROS1. N Engl J Med 368(25):2395-2401

16. Berman HM, Westbrook J, Feng Z, Gilliland G, Bhat TN, Weissig H, Shindyalov IN, Bourne PE (2000) The protein data bank. Nucleic Acids Res 28:235-242

17. Kim S, Chen J, Cheng T, Gindulyte A, He J, He S, Zaslavsky L (2019) PubChem 2019 update: improved access to chemical data. Nucleic Acids Res 47(D1):D1102-D1109

18. BIOVIA, Dassault Systèmes, BIOVIA Discovery Studio, Release 2018, San Diego: Dassault Systems, 2018. https://www.3ds.com/products-services/ biovia/resource-center/citations-and-references/

19. Rao SN, Head MS, Kulkarni A, LaLonde JM (2007) Validation studies of the site-directed docking program LibDock. J Chem Inf Model 47(6):2159-2171

20. Diller DJ, Merz KM Jr (2001) High throughput docking for library design and library prioritization. Proteins 43:113-124. https://doi.org/10.1002/ 1097-0134(20010501)43:2<113::AID-PROT1023>3.0.CO;2-T

21. Brooks BR, Brooks CL III, Mackerell AD Jr, Nilsson L, Petrella RJ, Roux B, Karplus M (2009) CHARMM: the biomolecular simulation program. J Comput Chem 30(10):1545-1614

22. Peng YH, Shiao HY, Tu CH, Liu PM, Hsu JTA, Amancha PK, Lin WH (2013) Protein kinase inhibitor design by targeting the Asp-Phe-Gly (DFG) motif: the role of the DFG motif in the design of epidermal growth factor receptor inhibitors. J Med Chem 56(10):3889-3903

23. Wang T, Pickard AJ, Gallo JM (2016) Histone methylation by Temozolomide; a classic DNA methylating anti-cancer drug. Anti-cancer Res 36(7):3289-3299

24. Pang CNI, Gasteiger E, Wilkins MR (2010) Identification of Arginine- and lysine-methylation in the proteome of Saccharomyces cerevisiae and its functional implications. BMC Genomics 11:92. https://doi.org/10.1186/ 1471-2164-11-92

25. Clarke S (1993) Protein methylation. Curr Opin Cell Biol 5(6):977-983. https://doi.org/10.1016/0955-0674(93)90080-a

26. Murn J, Shi Y (2017) The winding path of protein methylation research: milestones and new frontiers. Nat Rev Mol Cell Biol 18(8):517-527. https://doi.org/10.1038/nrm.2017.35

27. Paik WK, Paik DC, Kim S (2007) Historical review: the field of protein methylation. Trends Biochem Sci 32(3):142-152. https://doi.org/10.1016/j.tibs. 2007.01.006

28. Carlson SM, Gozani O (2016) Nonhistone lysine methylation in the regulation of cancer pathways. Cold Spring Harb Perspect Med 6(11):a026435. https://doi.org/10.1101/cshperspect.a026435

29. Lin CH, Chang TT, Sun MF, Chen HY, Tsai FJ, Chang KL, Chen CYC (2011) Potent inhibitor design against H1N1 swine influenza: structure-based and molecular dynamics analysis for M2 inhibitors from traditional Chinese medicine database. J Biomol Struct Dyn 28(4):471-482

30. Wang W, Li X, Wang Q, Zhu X, Zhang Q, Du L (2018) The acidic pHinduced structural changes in apo-CP43 by spectral methodologies and molecular dynamics simulations. J Mol Struct 1152:177-188

31. Hyndman RJ, Koehler AB (2006) Another look at measures of forecast accuracy. Int J Forecast 22(4):679-688

32. Xi L, Wang Y, He Q, Zhang Q, Du L (2016) Interaction between Pin1 and its natural product inhibitor epigallocatechin-3-gallate by spectroscopy and molecular dynamics simulations. Spectrochim Acta Part A Mol Biomol Spectrosc 169:134-143

33. Butt AM, Feng D, Idrees M, Tong Y, Lu J (2012) Computational identification and modeling of crosstalk between phosphorylation, O- $\beta$ glycosylation and methylation of FoxO3 and implications for cancer therapeutics. Int J Mol Sci 13(3):2918-2938

\section{Publisher's Note}

Springer Nature remains neutral with regard to jurisdictional claims in published maps and institutional affiliations. 